\title{
Near-Infrared Fluorescence Imaging in Humans with Indocyanine Green: A Review and Update
}

\author{
Milton V. Marshall ${ }^{1}$, John C. Rasmussen ${ }^{1}$, I-Chih Tan ${ }^{1}$, Melissa B. Aldrich ${ }^{1}$, Kristen E. Adams ${ }^{1}$, \\ Xuejuan Wang ${ }^{1}$, Caroline E. Fife ${ }^{2}$, Erik A. Maus ${ }^{2}$, Latisha A. Smith ${ }^{2}$ and Eva M. Sevick-Muraca ${ }^{*}$ \\ ${ }^{I}$ Center for Molecular Imaging, The Brown Foundation Institute of Molecular Medicine, The University of Texas Health \\ Science Center, Houston, Texas 77030, USA \\ ${ }^{2}$ Department of Internal Medicine, Division of Cardiology and Hyperbaric Medicine at The University of Texas Health \\ Science Center and Memorial Hermann Center for Lymphedema Management, Houston, TX 77030, USA
}

\begin{abstract}
Near-infrared (NIR) fluorescence imaging clinical studies have been reported in the literature with six different devices that employ various doses of indocyanine green (ICG) as a non-specific contrast agent. To date, clinical applications range from (i) angiography, intraoperative assessment of vessel patency, and tumor/metastasis delineation following intravenous administration of ICG, and (ii) imaging lymphatic architecture and function following subcutaneous and intradermal ICG administration. In the latter case, NIR fluorescence imaging may enable new discoveries associated with lymphatic function due to (i) a unique niche that is not met by any other conventional imaging technology and (ii) its exquisite sensitivity enabling high spatial and temporal resolution. Herein, we (i) review the basics of clinical NIR fluorescence imaging, (ii) survey the literature on clinical application of investigational devices using ICG fluorescent contrast, (iii) provide an update of non-invasive dynamic lymphatic imaging conducted with our FDPM device, and finally, (iv) comment on the future NIR fluorescence imaging for non-invasive and intraoperative use given recent demonstrations showing capabilities for imaging following microdose administration of contrast agent.
\end{abstract}

Keywords: Optical imaging, angiography, lymphatics, intraoperative imaging, non-invasive fluorescence imaging.

\section{INTRODUCTION}

When compared to the blood vasculature, the unidirectional lymphatic circulatory system offers unique challenges for intraoperative visualization and non-invasive imaging. The peripheral lymphatic system begins at the lymphatic capillary plexus that underlies the dermis and lines several organs; and it consists of overlapping lymph endothelial cells that open under elevated interstitial pressure, enabling entry of foreign materials and interstitial fluid. From the plexus, the colorless lymph is transported through collecting vessels via the action of contractile lymphangions to regional lymph nodes (LNs), where immune surveillance occurs. From the LNs, filtered lymph is propelled back to the blood circulation via the subclavian vein to maintain tissue fluid homeostasis. In the mesentery, the lymphatics have an additional function of absorbing fatty acids and lipid soluble vitamins for delivery to the blood circulation (for review see Alitalo, 2005 [1]). Given its multiple functionality, it may not be surprising that a complete failure of the lymphatics results in a dramatic, irreversible condition of chronic edema, tissue fibrosis, and susceptibility to infection that together constitute the disease known as lymphedema. Lymphedema is broadly classified into two categories of (i) primary or hereditary disease that has been associated thus far with three mutations in genes

*Address correspondence to this author at the Center for Molecular Imaging, The Brown Foundation Institute of Molecular Medicine, The University of Texas Health Science Center, Houston, Texas 77030, USA; Tel: 713-500-3560; E-mail: Eva.sevick@uth.tmc.edu associated with lymphatic development, and (ii) secondary or acquired disease in which trauma is thought to be the initiating event for the onset of excessive edema (for review see Rockson [2]). It is estimated that as many as $40 \%$ of all breast cancer patients who undergo axillary lymph node dissection (ALND) [3-5] and 64\% of all cancer patients who undergo groin lymph node dissection [6] succumb to acquired lymphedema. Recent evidence suggests that there may be a genetic predisposition for the acquired form of the disease following cancer surgery [7]. Regardless of the classification, if untreated, lymphedema most likely progresses to fibrosis, pain/paresthesias, extreme disfigurement, reduced immune surveillance, and lymphangiosarcoma, also known as Stewart-Treves syndrome [8]. Although lymphedema represents the most extreme case of dysfunctional lymphatics, abnormal lymphatic function may also be responsible for a wide spectrum of diseases including obesity [9], diabetes [10], asthma [11], and is intimately involved in cancer metastasis [12]. The lack of imaging to obtain structural or functional information currently limits our understanding of the role of lymphatics in disease and impedes the development of therapeutic interventions [13].

For example, although CT and MR angiographies that employ iodinated- or gadolinium-based contrast agents are well established for evaluating structural abnormalities of the blood vasculature, their use for lymphangiography is complicated by the challenges to locate and cannulate lymphatic vessels for contrast agent administration. Doppler ultrasound is typically used for imaging functional abnormalities in the blood vasculature on the basis of 
Doppler backscatter from moving red blood cells, but owing to the paucity of cells in lymph, the lymphatics escape interrogation using this conventional vascular imaging modality. Gamma scintigraphy employs subcutaneous or intradermal radiocolloid injections to identify the lymph node basins draining the site of injection [14], but typically does not have the spatial resolution to detect distinct lymphatic vessels nor the temporal resolution to discriminate the contractile lymphatic function that is responsible for lymph transport or lack thereof.

Intraoperatively, the lymphatics can be detected through intradermal injection of vital dye, such as isosulfan blue, Patent Blue, methylene blue, or indocyanine green (ICG) to directly visualize the lymph vessels draining from the injection site to the nearest sentinel or regional lymph node. Given the lack of conventional imaging modalities available for non-invasive evaluation of the lymphatics, no contrast agents are available to molecularly target and image the lymphatics, whether targeting markers of lymphangiogenesis (i.e., the process of lymphatic vessel formation postulated to be associated with cancer metastasis, wound repair, or inflammation) or other yet unknown biological markers of disease states.

Recently, near-infrared (NIR) fluorescence imaging has been demonstrated to offer exquisite sensitivity enabling non-invasive assessment of both lymphatic architecture and function as well as potential disease markers of lymphatic dysfunction. NIR fluorescence imaging and tomography involves administration of a fluorescent contrast agent that (i) can be excited at wavelengths of $780 \mathrm{~nm}$ or greater, and (ii) has a significant Stoke's shift emitting fluorescence at wavelengths of $800 \mathrm{~nm}$ or greater. In this contribution, we briefly review (i) the basics of NIR imaging, (ii) the rationale and prior use of ICG as an NIR fluorophore for intraoperative visualization and non-invasive imaging of the blood and lymph vasculatures, and finally, (iii) provide an update of non-invasive NIR imaging of lymphatic structure and function in health and disease. We summarize by describing the future application of NIR fluorescence using fluorophores (other than ICG) that will be required for NIR fluorescence molecular imaging.

\section{THE BASICS OF NIR FLUORESCENCE IMAGING}

Owing to its sensitivity, nuclear imaging with radionuclides represents the clinical standard for molecular imaging. Yet when compared to radionuclides used for nuclear imaging, NIR fluorophores may provide higher sensitivity for intraoperative and non-invasive imaging due to their ability to be repeatedly excited by tissue-penetrating NIR excitation light. For example, consider the average nanosecond time delay between the absorption of an excitation photon by a fluorophore and the emission of a fluorescent photon, after which the fluorophore returns to its ground state. Once in its ground state, the fluorophore is again available for activation by propagating excitation light. Under these conditions, a fluorophore can emit as many as $100,000,000$ photons per second per molecule, compared to the single relaxation of a radionuclide that gives at most a single photon event. However, the photon energies from radionuclide decay ranges from $100-511 \mathrm{keVs}$ while visible and visible fluorescent emissions are on the order 100,000 times less energetic. As a consequence, excitation and fluorescent light experiences considerably greater tissue attenuation and scattering than the higher energy gamma or annihilation photons collected in nuclear imaging techniques. The basis of NIR fluorescence imaging and tomography through deep tissue sections depends upon the low absorbance but high scattering properties of tissues in the wavelength range of $600-1000 \mathrm{~nm}$, enabling diffuse propagation and deep tissue penetration. Of this "therapeutic wavelength" range between $600-1000 \mathrm{~nm}$, only a small wavelength window in the NIR region $(>750 \mathrm{~nm})$ is feasible for non-invasive imaging of deep tissues without the contribution of autofluorescence $[15,16]$. To illustrate the impact of autofluorescence, Fig. (1a) provides a simple example in which a vial of $50 \mathrm{nM}$ of a NIR-excitable fluorescent dye, IRDye $800 \mathrm{CW}$, and a mouse containing no dye, are illuminated with $785 \mathrm{~nm}$, NIR excitation light. The resulting fluorescence image collected at $830 \mathrm{~nm}$ illustrates that there is no endogenous autofluorescence. Owing to the low noise floor that has no contribution from autofluorescence, the figure shows that in vivo detection of IRDye $800 \mathrm{CW}$ at tissue concentrations less than $50 \mathrm{nM}$ is possible in vivo. In contrast, Fig. (1b) shows the same example, using $690 \mathrm{~nm}$ excitation of a vial containing $50 \mathrm{nM}$ of a red excitable fluorescent dye, Cy5.5, and a mouse without any Cy5.5 dye. The resulting fluorescent image of the mouse at $710 \mathrm{~nm}$ shows endogenous autofluorescence that establishes a noise floor which would prevent detection of tissue concentrations of $50 \mathrm{nM}$ or less [15]. Cleary, the sensitivity of NIR excitable dyes exceeds other blue-shifted dyes owing to autofluorescence. Herein, we restrict our review and remaining comments to clinical studies using ICG as it is the only NIR fluorophore used in human studies of NIR fluorescence.

Upon inspection of Fig. (1a), one may additionally notice the faint outline of the mouse that arises from "leakage" through the interference filters used to reject the backscattered excitation light and pass only the fluorescent light. Filter light leakage currently represents the limiting noise floor for NIR fluorescence imaging because in practice, it is nearly impossible to perfectly reject all reflected excitation light (as well as ambient light) to selectively collect only the comparatively weaker fluorescence signal [16-18]. However, by matching tissue illumination sources with proper interference filters that reject several orders of magnitude of backscattered excitation light intensity, the noise floor can be minimized. As shown in Section 3, a sufficient level of excitation light leakage enables identification of tissue boundaries and can be advantageous if properly controlled. However, if excitation light leakage creates a noise floor higher than the fluorescent signal from the NIR fluorescent contrast agent, then the sensitivity of the imaging device will be reduced. Since the intensity of emanating fluorescent signal attenuates with depth, the depth of penetration is also reduced with increased light leakage through the filters. It is important to note that the greater the wavelength bandwidth of the excitation source (as in the case of a laser emitting diode (LED)), then the more difficult to selectively reject the backscattered excitation light while efficiently collecting the fluorescent light. Currently, the limit of sensitivity of all investigational 

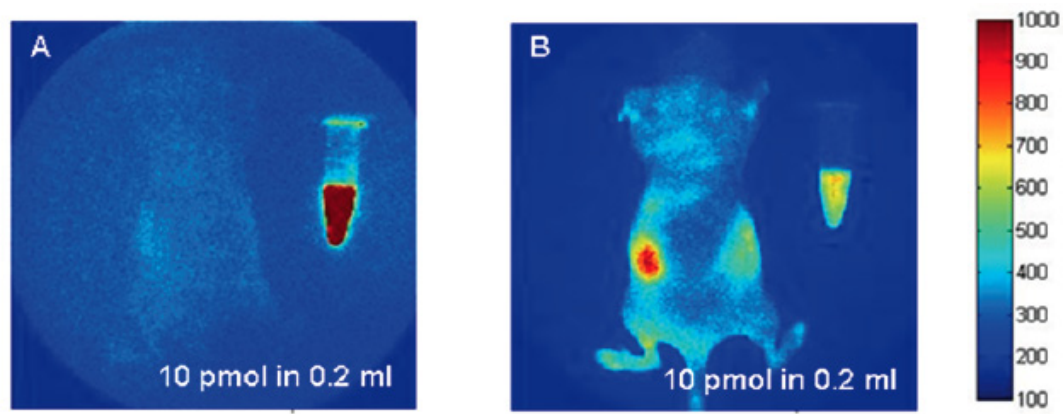

Fig. (1). (A) Fluorescent image taken following NIR excitation at $785 \mathrm{~nm}$ and collection of fluorescence at $835 \mathrm{~nm}$ showing a mouse containing no fluorophore and a vial containing $50 \mathrm{nM}$ of NIR fluorophore, IRDye800CW. (B) Fluorescent image taken following red excitation at $690 \mathrm{~nm}$ and collection of fluorescence at $710 \mathrm{~nm}$ showing a mouse containing no fluorophore and a vial containing $50 \mathrm{nM}$ of Cy5.The images show dramatically more autofluorescence that creates elevated background at red (690 $\mathrm{nm})$ than at NIR (785 $\mathrm{nm})$ excitation wavelengths. Reproduced with permission from Adams, et al. [15].

Table 1. Devices Used for Clinical Trials of ICG Fluorescence Imaging

\begin{tabular}{|c|c|c|c|c|c|c|c|}
\hline Device & Excitation Source & $\begin{array}{l}\text { Fluorescence } \\
\text { Collection }\end{array}$ & Detector & $\begin{array}{l}\text { Working } \\
\text { Distance }\end{array}$ & $\begin{array}{l}\text { Field of } \\
\text { View }\end{array}$ & $\begin{array}{l}\text { Depth of } \\
\text { Penetration }\end{array}$ & $\begin{array}{c}\text { Integration } \\
\text { Time or } \\
\text { Frames Per } \\
\text { Sec (FPS) }\end{array}$ \\
\hline $\begin{array}{l}\text { Photodynamic Eye } \\
\text { (PDE) Hamamatsu }\end{array}$ & $\begin{array}{l}\text { Laser emitting diodes } \\
\text { (LEDs) centered at } 760 \\
\text { nm, incident power not } \\
\text { specified }\end{array}$ & $\begin{array}{l}\text { Bandpass filter } \\
>820 \mathrm{~nm}\end{array}$ & CCD & $20 \mathrm{~cm}$ & $\begin{array}{l}\text { Not given, } \\
\text { but limited }\end{array}$ & $2 \mathrm{~cm}$ & $\begin{array}{c}\text { Not } \\
\text { specified }\end{array}$ \\
\hline SPY (Novadaq) & $\begin{array}{l}\text { Laser emitting at } 806 \mathrm{~nm} \text {, } \\
2.0-2.7 \mathrm{~W}, \text { incident } \\
\text { power not specified }\end{array}$ & $\begin{array}{c}835 \mathrm{~nm} \text { "camera," } \\
\text { not specified }\end{array}$ & CCD & $30 \mathrm{~cm}$ & $56 \mathrm{~cm}^{2}$ & $1 \mathrm{~mm}$ DOP & $30 \mathrm{fps}$ \\
\hline $\begin{array}{l}\text { FDPM imager } \\
\quad \text { (Texas) }\end{array}$ & $\begin{aligned} \text { Laser Diode, } 785 \pm 10 \mathrm{~nm}, & <1.9 \mathrm{~mW} / \mathrm{cm}^{2}\end{aligned}$ & $\begin{array}{l}\text { Notch filters at } \\
785 \mathrm{~nm} \text {, and at } \\
830 \mathrm{~nm}\end{array}$ & $\begin{array}{l}\text { Gen III intensifier } \\
\text { coupled to CCD, } \\
\text { gain modulatable } \\
\text { for tomography }\end{array}$ & $\begin{array}{l}\text { Variable, } \\
\text { but } \\
\text { reported } \\
<76.2 \mathrm{~cm}\end{array}$ & $\begin{array}{l}\text { Max } \\
\text { reported } \\
\text { FOV } 900 \\
\mathrm{~cm}^{2}\end{array}$ & $\begin{array}{l}\text { Estimated to } \\
\text { be } 4 \mathrm{~cm}\end{array}$ & $\begin{array}{c}50-800 \\
\text { msec }\end{array}$ \\
\hline $\begin{array}{c}\text { IC-View } \\
\text { (Pulsion Medical) }\end{array}$ & $\begin{array}{l}\text { Laser Diode } 780 \mathrm{~nm} \\
(0.16 \mathrm{~W}), \text { incident power } \\
\text { not specified }\end{array}$ & Not specified & $\mathrm{CCD}$ & $\begin{array}{c}\text { Not } \\
\text { specified }\end{array}$ & $\begin{array}{c}\text { Not } \\
\text { specified }\end{array}$ & $\begin{array}{c}\text { Not } \\
\text { specified }\end{array}$ & $\begin{array}{c}\text { Not } \\
\text { specified }\end{array}$ \\
\hline $\begin{array}{c}\text { FLARE (Israel Beth } \\
\text { Deaconess } \\
\text { Hospital) }\end{array}$ & $\begin{array}{l}\text { LEDs emitting 745-779 } \\
\mathrm{nm}, 14 \mathrm{~mW} / \mathrm{cm}^{2}\end{array}$ & $\begin{array}{l}\text { Bandpass filter } \\
800-848 \mathrm{~nm}\end{array}$ & $\mathrm{CCD}$ & $45 \mathrm{~cm}$ & $\begin{array}{l}3.7 \mathrm{~cm}^{2}- \\
169.5 \mathrm{~cm}^{2}\end{array}$ & $\begin{array}{c}\text { Not } \\
\text { specified }\end{array}$ & $200 \mathrm{msec}$ \\
\hline $\begin{array}{l}\text { Custom system } \\
\text { (Kochi Medical } \\
\text { School) }\end{array}$ & $\begin{array}{l}\text { LEDs emitting light } \\
\text { centered at } 760 \mathrm{~nm} \text {, } \\
\text { incident power not } \\
\text { specified }\end{array}$ & $\begin{array}{l}840 \text { nm cut-on } \\
\text { filter }\end{array}$ & Color CCD & $\sim 50 \mathrm{~cm}$ & $78.5 \mathrm{~cm}^{2}$ & $\begin{array}{c}\text { Not } \\
\text { specified }\end{array}$ & $\begin{array}{c}\text { Not } \\
\text { specified }\end{array}$ \\
\hline
\end{tabular}

NIR fluorescence camera systems is set by the light leakage through filters.

Table 1 lists the six investigational devices employed in the published studies described later in this review. The Photodynamic Eye (or PDE) from Hamamatsu uses LEDs emitting a range of wavelength centered at $760 \mathrm{~nm}$ within a handheld unit that uses a bandpass filter to block light $<820$ $\mathrm{nm}$ from reaching an intensified charge coupled device (CCD). The majority of intraoperative and non-invasive investigational studies have used the PDE system following administration of $\mathrm{mg}$ amounts of ICG and report depth limitations of $2 \mathrm{~cm}$ and working distances between unit and tissue that are limited to $20 \mathrm{~cm}$. The IC-View system from Pulsion Medical employs a laser diode emitting at $785 \mathrm{~nm}$ and unspecified filters to collect fluorescence at $835 \mathrm{~nm}$ onto a CCD. The device has shown utility in both transcutaneous as well as intraoperative imaging following administration of $\mathrm{mg}$ amounts of ICG [19]. The system developed in the 1990 's for canine studies [20,21] and translated to clinical trials within the Texas Medical Center in Houston [22] employs a $785 \mathrm{~nm}$ laser diode and holographic filter to block the backscattered excitation light as well as a notch bandpass centered at $830 \mathrm{~nm}$ for efficient fluorescence light collection on a Gen III IR-sensitive intensifier coupled to a CCD. The system is used exclusively for non-invasive human imaging following administration of $\mu \mathrm{g}$ amounts of ICG and has capabilities for 3-D tomography as demonstrated in phantoms and small animals [16]. The FLARE system developed at Beth Israel Deaconess Hospital in Boston, MA consists of LEDs emitting between 745 and $779 \mathrm{~nm}$ and uses a bandpass enabling collection of light $>800 \mathrm{~nm}$ onto a CCD. In humans, this system has been used intraoperatively [23]. Finally, the SPY system from Novadaq has been used exclusively intraoperatively to determine blood vessel and graft patency and employs an 806 laser diode, reportedly of 
2.2-2.7 W power, for collection of fluorescence at $835 \mathrm{~nm}$ [24]. The SPY system has been cleared by the Food and Drug Administration (FDA) exclusively for intraoperative imaging following intravenous administration of ICG. The final system, developed in the Kochi Medical School in Japan, uses LEDs, a cut-on filter passing light $>840 \mathrm{~nm}$, and a color CCD camera for intraoperative assessment of coronary artery bypass surgery [25]. Each of the six systems differs in the power, wavelength and bandwidth of excitation sources, and filtering strategy for rejection of backscattered excitation and ambient light that establishes the sensitivity level of the device.

If light leakage through the filters is not properly controlled, instrument sensitivity declines and the amount of fluorophore must be increased to collect a fluorescent image. The "holy grail" of using molecularly targeted NIR fluorescence agents to guide surgical resection or non-invasively detect diseased tissues on the basis of a disease marker requires the ability to detect less than picomolar concentrations of agent within tissues. Reduction of autofluorescence by a choice of NIR fluorescent dyes, and the reduction of light leakage with properly designed equipment, critically increases the sensitivity of NIR imaging. With background sources of autofluorescence and leakage corrected, camera integration times can be lengthened in order to detect NIR fluorescence emanating from deeper tissues.

\section{ICG AS AN NIR FLUORESCENT CONTRAST AGENT IN INVESTIGATIONAL HUMAN STUDIES}

Currently in the US, no NIR fluorophores are approved for human use, although there are efforts to translate new NIR fluorophores that can be conjugated to peptides, affibodies, and antibodies, etc. for molecular imaging [26]. ICG is a tricarbocynanine dye that has been used clinically for over 50 years for hepatic clearance, cardiovascular function testing, and retinal angiography on the basis of its dark green color, typically administered at concentrations of $2.5 \mathrm{mg} / \mathrm{ml}$ at typical total doses of $25 \mathrm{mg}$ in adults. Because ICG has no functional groups for conjugation to targeting moieties for molecular imaging application, it is a nonspecific contrast agent. ICG does associate with albumin, making it an excellent vascular agent for evaluating both the blood and lymph systems in off-label studies. Although ICG can be excited between 760 and $785 \mathrm{~nm}$ and the fluorescence imaged between 820 and $840 \mathrm{~nm}$, compared to other NIR fluorophores, ICG has weak fluorescent properties. Due to its instability, ICG must be used within 10 hours of reconstitution in saline.

Because of its NIR fluorescent properties, ICG has recently been used in off-label clinical studies for intraoperative identification of LNs and patency of lymph and blood vessels, as well as non-invasive assessment of lymphatic function. In this review, we focus on the use of ICG as the only NIR fluorophore employed to date for human use. A summary of recent reports of clinical studies employing the fluorescent properties of ICG using NIR light excitation are provided in Table $\mathbf{2}$ and are briefly described below.

\subsection{Sentinel Lymph Node Mapping}

The majority of the studies listed in Table $\mathbf{2}$ involve intraoperative identification and dissection of sentinel lymph nodes (SLNs) for cancer staging in breast, skin, and gastric cancers. Currently, intraoperative mapping is performed in the United States by injecting $\sim 1 \mathrm{mg} / \mathrm{ml}$ isosulfan blue dye (Lymphazurin) subcutaneously or intradermally for direct visualization of lymphatic vessels and their draining LN basins in order to surgically resect LNs; Patent Blue is more commonly used in Europe and Japan [27, 28]. When injected intradermally (typically with volumes of $0.1 \mathrm{cc}$ ), the lymphatic capillary plexus quickly "picks" up the blue dye and stains the lymphatics as it is transited through conducting lymphatic vessels to the sentinel (or closest draining LN) and to the regional LN basins. Larger $3-5 \mathrm{cc}$ volumes of subcutaneous injections of blue dye likewise result in uptake into the lymphatic vessels, albeit not as quickly as when smaller volumes are injected intradermally. When injected at high enough concentrations, ICG likewise causes green "staining" of lymphatic vessels as it progresses to the draining LNs, which also become green and directly visible without the needed use of NIR fluorescence. Motomura et al. [29] injected $25 \mathrm{mg}$ subcutaneously for direct visualization of tumor-draining LNs in breast cancer patients, while Ichikura et al. [30], Yaguchi, et al. [31], and Park et al. [32] likewise injected $5-7.5 \mathrm{mg}$ and $25 \mathrm{mg}$ subcutaneously to visualize SLNs in gastric cancer patients. Given that both ICG and blue dyes both bind to globulin proteins within tissues, it may not be surprising that they are both avidly taken up by the lymphatics and that SLN mapping with ICG staining correlates well with standard blue dye staining $[33,34]$. Nonetheless, the added advantage of using the fluorescent properties of ICG when using these high doses may be the ability to visualize draining lymph nodes located beneath overlying tissues. For example, the results presented by Miyashiro et al. [35], suggest that detection of SLNs in gastric cancer using fluorescence laparoscopic procedures are possible following 5-10 $\mathrm{mg}$ of ICG administered subcutaneously. Transcutaneous (or noninvasive) fluorescence imaging of lymph vessels and LNs has also been demonstrated with ICG. Kitai et al. [36] were able to visualize LNs and lymph vessels draining the breast following $25 \mathrm{mg}$ of ICG administered subcutaneously prior to fluorescence-guided resection of LNs. Similar transcutaneous fluorescence imaging and fluorescenceguided LN resection with mg quantities of ICG has also been demonstrated for nodal staging in skin cancer [33, 37, 38], breast cancer [34, 39], and rectal cancer [40]. These studies suggest that for superficial tumor-draining lymph node basins, NIR fluorescence could supplant lymphoscintigraphy, which is typically performed with administration of ${ }^{99 \mathrm{~m}} \mathrm{Tc}$ radiocolloid followed by gamma camera imaging for surgical planning and nuclear and gamma probe interrogation for intraoperative localization. Indeed, several studies suggest similar performance of lymphoscintigraphy and ICG fluorescence for identification of SLNs [19, 30, 31, 37]. Although the advantages of using a non-radiative, non-specific probe such as ICG are significant, it remains unclear whether they are great enough to warrant the replacement of the blue dye (administered at comparable doses that ICG was administered above) and/or ${ }^{99 \mathrm{~m}} \mathrm{Tc}$ radiocolloid as non-specific agents for resecting $\mathrm{LNs}$ for cancer staging. 
Table 2. Clinical Applications of Devices Collecting ICG Fluorescence Imaging

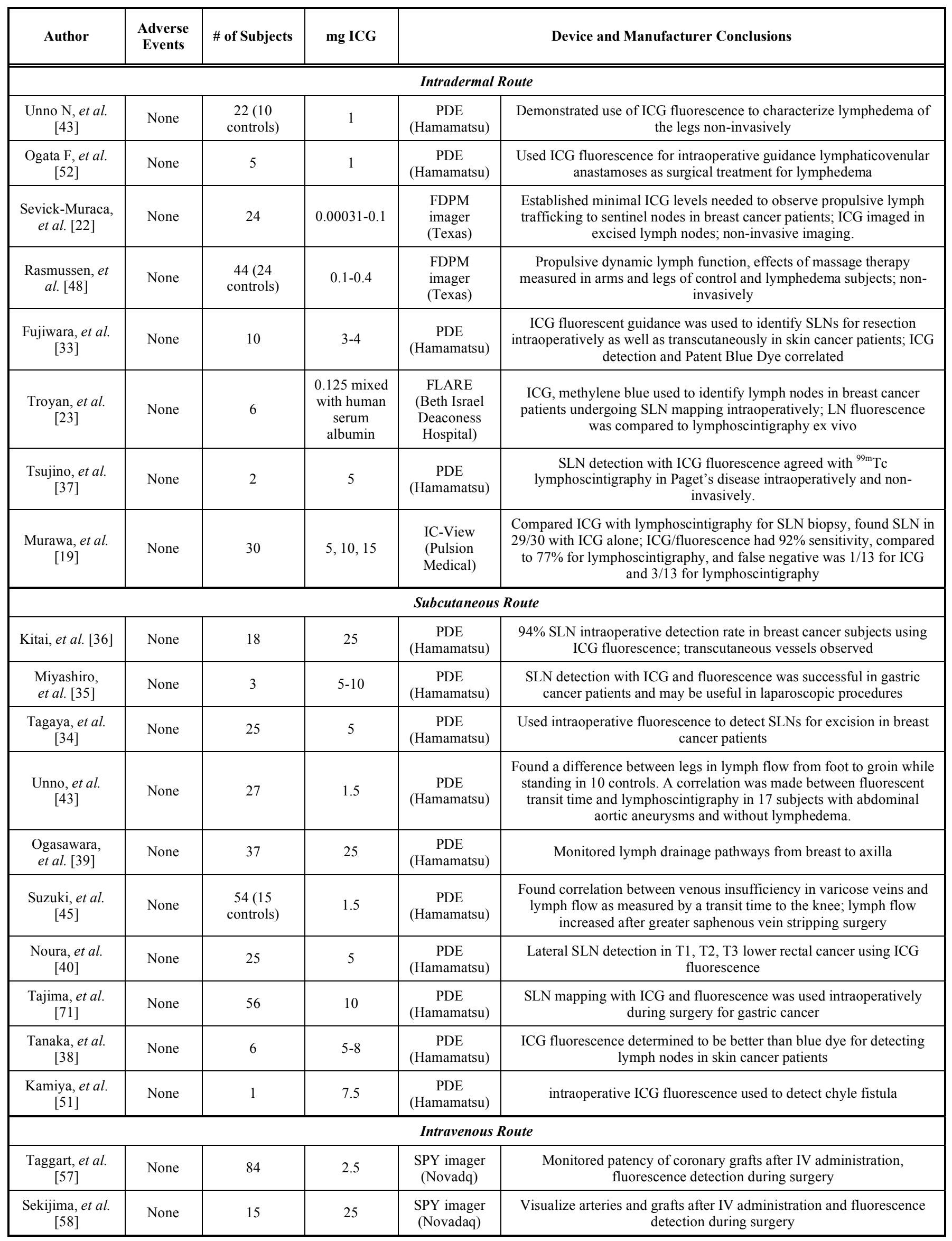




\begin{tabular}{|c|c|c|c|c|c|}
\hline Author & $\begin{array}{l}\text { Adverse } \\
\text { Events }\end{array}$ & \# of Subjects & mg ICG & & Device and Manufacturer Conclusions \\
\hline $\begin{array}{l}\text { Balacum- } \\
\text { araswami, et al. } \\
\quad[54,55]\end{array}$ & None & 200 & $0.03 \mathrm{mg} / \mathrm{kg}$ & $\begin{array}{l}\text { SPY imager } \\
\text { (Novadaq) }\end{array}$ & $\begin{array}{l}\text { Monitored patency of arterial grafts after IV administration and } \\
\text { fluorescence detection during surgery }\end{array}$ \\
\hline $\begin{array}{c}\text { Kikuchi and } \\
\text { Hosokawa [53] }\end{array}$ & None & 20 & $25 \mathrm{mg}$ & $\begin{array}{c}\text { PDE } \\
\text { (Hamamatsu) }\end{array}$ & $\begin{array}{l}\text { ICG fluorescence used non-invasively to assess impact of vein } \\
\text { stripping, phlebectomy, and vein ligation }\end{array}$ \\
\hline $\begin{array}{c}\text { Ishizawa et al. } \\
\text { [63] }\end{array}$ & None & $\begin{array}{c}37 \\
\text { hepatocellular } \\
\text { carcinoma, } \\
12 \text { metastatic } \\
\text { colorectal } \\
\text { cancer }\end{array}$ & $0.5 \mathrm{mg} / \mathrm{kg}$ & $\begin{array}{c}\text { PDE } \\
\text { (Hamamatsu) }\end{array}$ & $\begin{array}{l}\text { ICG fluorescence intraoperatively detected } 1-14 \text { days after i.v. } \\
\text { administration and correlated to lesions on the liver. Ex vivo ICG } \\
\text { fluorescence confirmed in resected tissues }\end{array}$ \\
\hline $\begin{array}{l}\text { Holm, et al. } \\
\quad[61]\end{array}$ & None & 15 & $0.5 \mathrm{mg} / \mathrm{kg}$ & $\begin{array}{l}\text { IC-View } \\
\text { (Pulsion } \\
\text { Medical) }\end{array}$ & $\begin{array}{l}\text { Perfusion of deep inferior epigastric perforator flap after tissue } \\
\text { reconstruction surgery by fluorescence }\end{array}$ \\
\hline $\begin{array}{l}\text { Handa, et al. } \\
{[25]}\end{array}$ & None & 39 & $\begin{array}{c}\text { Dose not } \\
\text { specified, } \\
\text { except that } \\
2.5 \mathrm{mg} / \mathrm{ml} \\
\text { was } \\
\text { concentration } \\
\text { of injected } \\
\text { dose }\end{array}$ & $\begin{array}{l}\text { Custom } \\
\text { (Koshi } \\
\text { Medical } \\
\text { School) }\end{array}$ & $\begin{array}{c}\text { Studies showed preliminary data showing feasibility of color CCD as a } \\
\text { intraoperative graft and perfusion assessment tool in coronary bypass } \\
\text { graft. }\end{array}$ \\
\hline
\end{tabular}

However, if NIR fluorescence imaging were demonstrated to have sufficient sensitivity for molecular imaging of cancer-positive lymph nodes, then the accuracy of nodal staging could be improved by non-invasively diagnosing the presence of cancer-positive lymph nodes and, if appropriate, direct their selective resection [41]. Yet, disease markers are typically present at pico- to femto- molar tissue concentrations, and molecular imaging of cancerpositive lymph nodes depends upon the sensitivity of the device and the use of a "first-in-humans" imaging agent. In a dose-escalation study to determine the minimum dose required for non-invasive fluorescence imaging of ICG using their camera system, Sevick-Muraca and coworkers [22] demonstrated non-invasive imaging of LNs and lymphatic vessels after administering as little as $0.01 \mathrm{mg}$ of ICG in breast cancer patients. Above that dose but below $0.1 \mathrm{mg}$, the study also established a general concordance of lymphoscintigraphy, isosulfan blue, and ICG fluorescence in resected lymph nodes. Similar concordance in a smaller offlabel usage study was recently demonstrated intraoperatively in excised LNs from breast cancer patients following 0.125 $\mathrm{mg}$ of ICG administered with albumin [23], but non-invasive imaging was unfortunately not reported.

The ability to non-invasively image NIR fluorescence following less than $0.1 \mathrm{mg}$ of contrast agent may facilitate the translation of brighter and molecularly specific "first-inhumans." Currently, International Conference on Harmonisation (ICH) and FDA guidances consider microdosage of "first-in-humans" drugs and imaging agents as doses less likely to cause adverse events. As a result, the requirements of initial safety and toxicity studies may be reduced for NIR fluorescent agents when coupled with devices that are sensitive enough to enable microdosing. The FDA defines a "microdose" as $1 / 100^{\text {th }}$ of the dose that yields a pharmacologic response (for therapeutics labeled with an imaging agent), $0.1 \mathrm{mg}$ or less of a labeled protein, or 30 nmol or less of a labeled biologic agent [42]. Upon labeling a cancer targeting moiety with a NIR fluorophore and administering under microdosing conditions, the opportunities for non-invasive nodal staging and intraoperative resection of cancer-positive LNs could substantially impact the accuracy of cancer staging while reducing the morbidity associated with acquired lymphedema as described in Section 1 above.

\subsection{Assessment of Lymphatic Vascular Structure and Function}

A second emerging application of ICG fluorescence imaging in humans involves the evaluation of the lymphatic vasculature in lymphovascular disorders. Unno, et al. [43] administered $1 \mathrm{mg}$ of ICG intradermally in the foot to map the lymphatic architecture in healthy control subjects as well as in subjects with lower extremity lymphedema. In their studies, they stitched together fluorescent images from smaller fields of view to map out the lymphatic vasculature in the legs of lymphedema subjects, and documented features of dilated vessels with proximal obliteration, and diffuse 
constellation-like patches of dye accumulation that they termed "Milky Way" features. Subsequent work using the same instrumentation utilized ICG transit times from the subcutaneous injection sites on the foot to the appearance of dye in the knee or the groin to quantify lymphatic function in the legs. Unno et al. [44], found ICG transit times correlated well with transport times of radiocolloid using standard lymphoscintigraphy. In their studies, these transit time measurements were used to assess lymphatic function in subjects with abdominal aneurysms. Suzuki, et al. [45] likewise used $1.5 \mathrm{mg}$ subcutaneous injections in the foot to find differences in lymphatic function from transit times following saphenous vein stripping.

In addition to the advantages of microdosing enabled by high imaging device sensitivity, high temporal resolution enables non-invasive assessment of contractile lymphatic function as first imaged in swine [46], mice [47], and in the arms and legs of humans [16, 48]. In Phase I human studies conducted with approval from the FDA and the University of Texas Health Science Institutional Review Board, ICG fluorescence was imaged with ICCD integration times of 50 - 200 milliseconds over large fields of view, enabling not only visualization of LNs and lymphatic channels, but also propulsive, contractile action of the lymphatic draining to the lymphatics. Normal subjects as well as subjects diagnosed with unilateral lymphedema were recruited following informed consent and injected intradermally with $25 \mu \mathrm{g}$ of ICG in $0.1 \mathrm{cc}$ volume at various sites on the limbs and imaged with the Frequency Domain Photon Migration (FDPM) imager as described in Table 2. As one example, we illustrate the imaging data of a normal subject who had left ALND for nodal staging of breast cancer 30 years prior to imaging, but who does not experience any symptoms of lymphedema. The fluorescent images of the left and right hand in Fig. (2a, b) show normal lymphatic architecture and function in the right hand, but comparatively fewer functional vessels in the left hand, possibly consistent with the earlier insult of ALND. Fig. (2c) shows fluorescent images of the medial right arm showing functional lymph vessels in her right arm. Comparatively fewer vessels were observed in the medial arm on the side of ALND (not shown for brevity). The online supplemental video \#1 provides a compilation of 200 millisecond exposures sequentially stacked together to create a near-real time movie of the propulsion of ICG labeled "packets" of lymph transiting in the right medial arm of this subject. Finally, Fig. (2d, e) show lymphatic drainage to the left and right axilla, with online supplemental videos \#2 and \#3 showing functional, contractile transport to the right and left axilla. Presumably, the transport of lymph to the left axilla (site of ALND 30 years prior) may be a reason why this subject does not experience symptoms of lymphedema. The ICG in the lymph vessels draining into the lymphatics is located deep within the arms, hence the fluorescence is multiply scattered and appears diffuse. FDPM tomography is under development to provide 3-D images that account and correct for tissue scatter [16].

Following dynamic acquisition, the image sequences from the FDPM imager (as shown in the supplemental videos) can be evaluated to quantify the apparent velocities and frequency of propulsive events as a direct measure of lymphatic function. In 24 normal control subjects, apparent

(A)

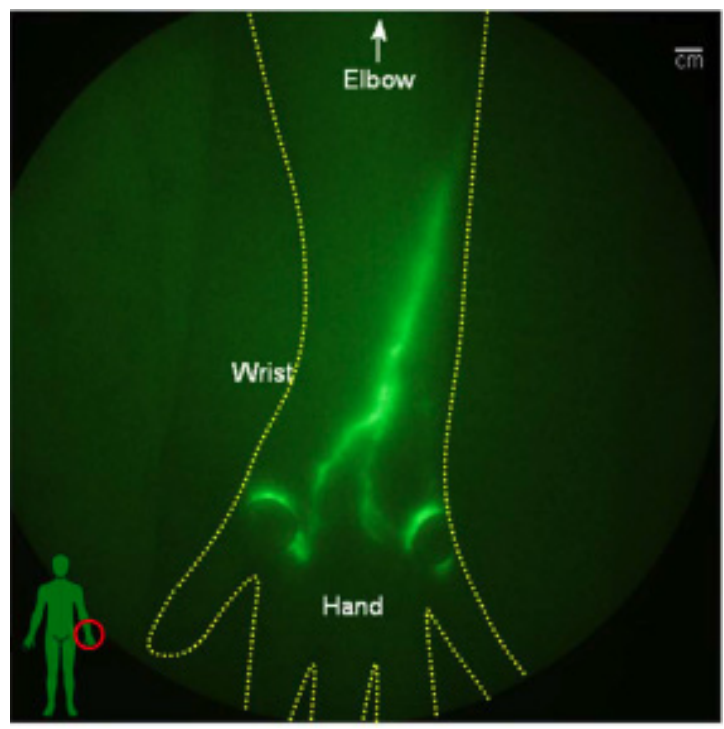

(B)

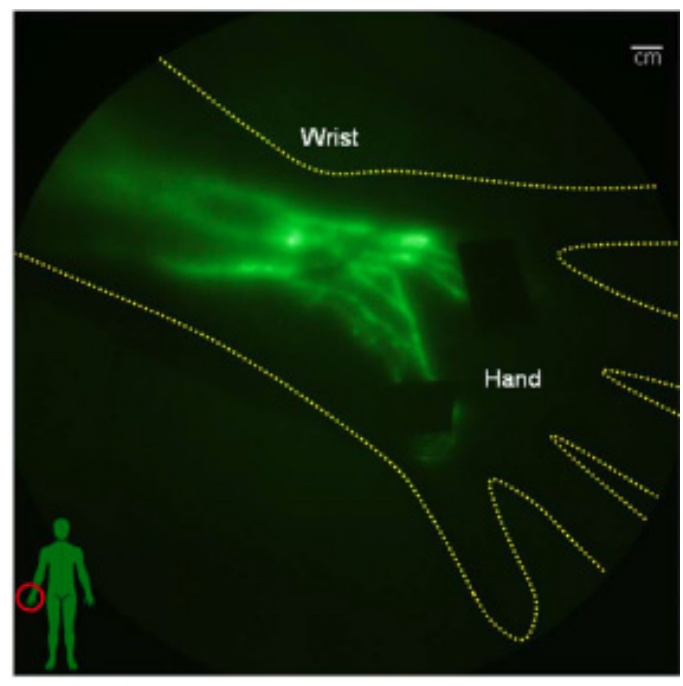

(C)

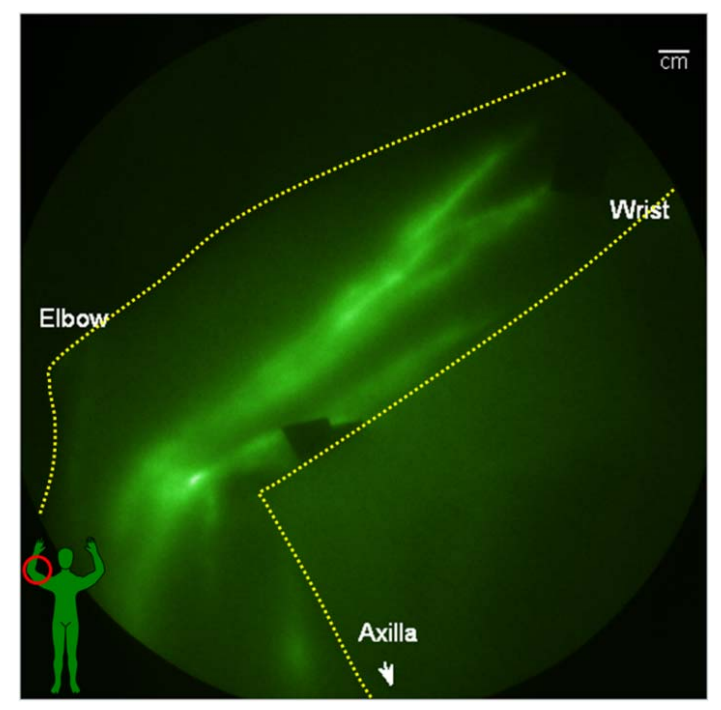


(Fig. 2) contd.....

(D)

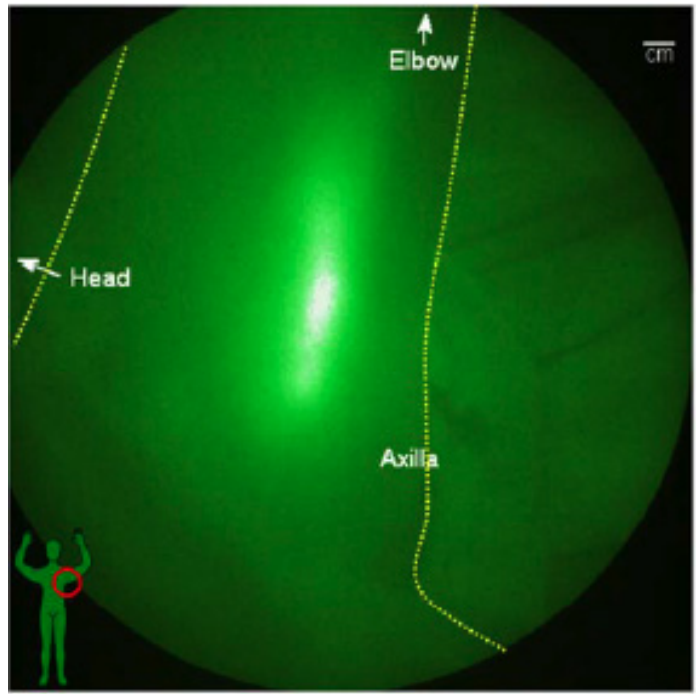

(E)

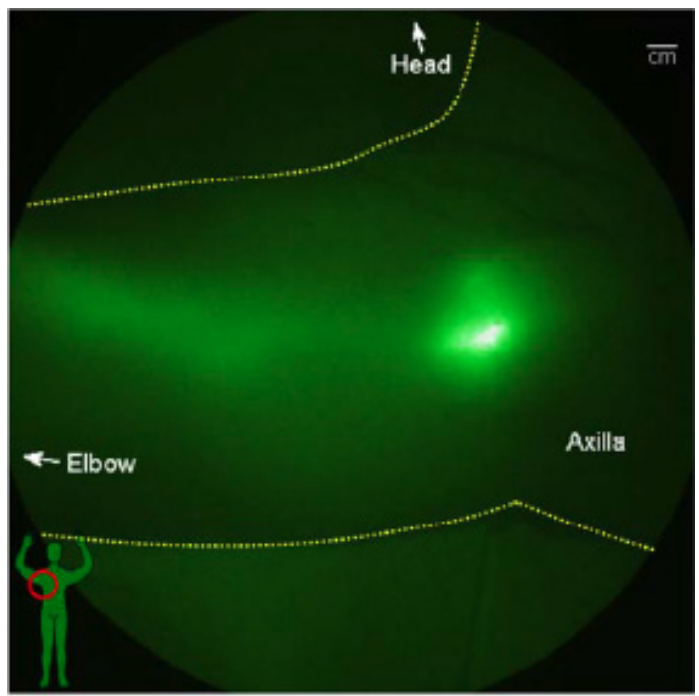

Fig. (2). NIR fluorescent images of the normal left and right arms of a woman who underwent cancer surgery and left ALND three decades previous to the date of imaging. The subject has no lymphedema, but NIR fluorescent images show (A) unusual lymphatic vasculature on the left hand, and (B) normal lymphatic vasculature on her right hand. NIR fluorescent images of her (C) medial right arm shows normal functioning lymphatic vessels (See online supplemental video \#1). NIR fluorescent images show drainage for both (D) left and (E) right axilla (See online supplemental videos \#2 and \#3).

lymph velocity ranges of $0.5-1.2 \mathrm{~cm} / \mathrm{sec}$ were found in normal arms, and $0.4-1.3 \mathrm{~cm} / \mathrm{sec}$ were found in normal legs. These values are considerably faster than the apparent velocities reported from lymphoscintigraphy. Average periods between lymph propulsive events ranged from 18.1 to $77.6 \mathrm{sec}$ in arms and 18.2 to $90.2 \mathrm{sec}$ in legs [49]. In almost all normal subjects, LNs draining the arms and legs were non-invasively detected. Fig. (3) illustrates the noninvasive imaging of LNs in the axilla, elbow, knee, and groin.
In lymphedema, lymphatic structure and function change considerably. Similar to reports by Unno et al. [43], several unique features were seen using the FDPM imager after microdose administrations of ICG in the limbs of 20 subjects diagnosed with unilateral Stage I or II lymphedema. Features included extravascular dye deposition in "milky way" constellation patterns, as well as in diffuse regions draining distal to the site of injection (Fig. 4a). In some LE subjects, dilated lymphatic vessels draining and feeding regions of hyperplastic dermal vessels (Fig. 4b) and tortuous lymphatic vessels (Fig. 4d) were visualized. In some cases, we observed reverse, active propulsion of lymph, as in the case of the distal flow to the fingers from the site of injection on the hand of a person with lymphedema (Fig. 4d) [47]. Using the FDPM imager, we found that the apparent lymph velocities measured in normal legs were significantly greater than those measured in the symptomatic or asymptomatic leg, but that there was no significant difference in lymph velocity between symptomatic and asymptomatic legs. Similar trends were seen in the frequency of propulsion in lymph "packets" in the arms of normal control subjects and subjects with unilateral lymphedema of the arm [49], again suggesting a systemic component to unilateral lymphedema. It is noteworthy that before NIR fluorescence imaging, no technique was capable of the sensitivity, temporal, and spatial resolution to quantify lymphatic function or dysfunction. More recently, we have employed NIR fluorescence imaging to quantify the functional response to manual decongestive therapies that are controversial, owing mainly to the lack of direct evidence of improvement of lymphatic function [50]. Because lymphatic function is directly assessed from contractile function rather than a timeto-appearance at a draining lymph node basin, the quantification can be conducted prior, during, and after therapies over a time course of 4 hours. Consequently, the approach can be used to guide the development of therapies that seek to alter lymphatic function. Other human investigations that involve use of ICG and NIR fluorescence imaging to direct therapy of lymphedema and lymphatic disorders include intraoperative identification of chyle fistula to direct surgery to alleviate chylothorax [51] as well as intraoperative guidance of lymphaticovenular anastomosis for reducing edema [52]. Clearly, NIR fluorescence imaging fills a unique need for evaluating lymphatic architecture and function.

\subsection{Vascular Repair}

Another unique niche for NIR fluorescence imaging is assessing vascular repair intraoperatively in settings where fluoroscopy is not available, or when administration of gadolinium-based or iodinated contrast agents is not warranted. In a recent study, Kikuchi and Hosokawa [53] injected $25 \mathrm{mg}$ of ICG intravenously to non-invasively image the vasculature of the lower extremities using NIR fluorescence. Their studies showed the ability to assess vascular function after vein ligation, vein stripping, and phlebectomy. Intraoperatively, intravenous administration of ICG and fluorescence imaging has been employed to assess patency of arterial grafts [54-57] and of transplanted organs [58]. In addition, ICG fluorescence has been used in 


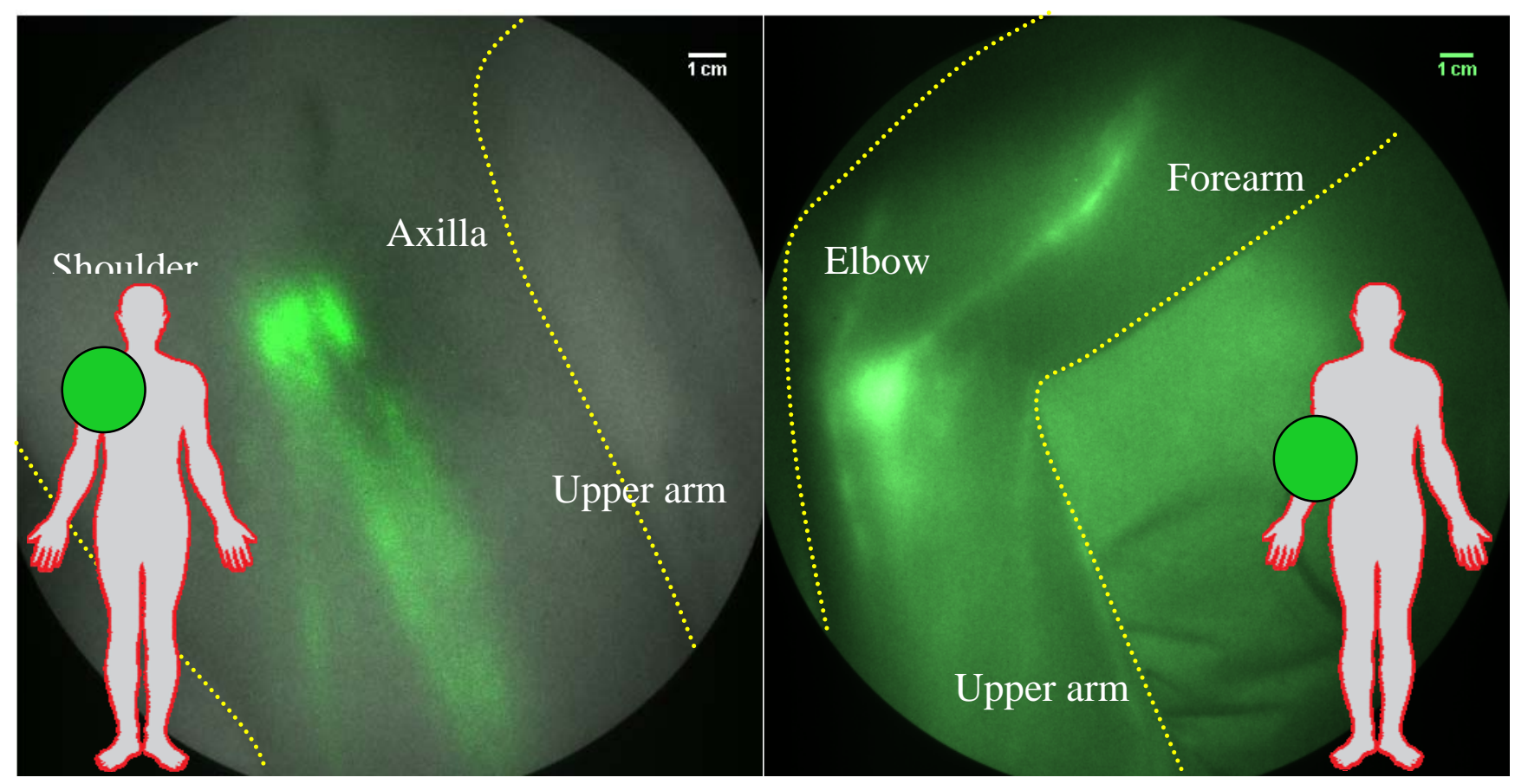

a

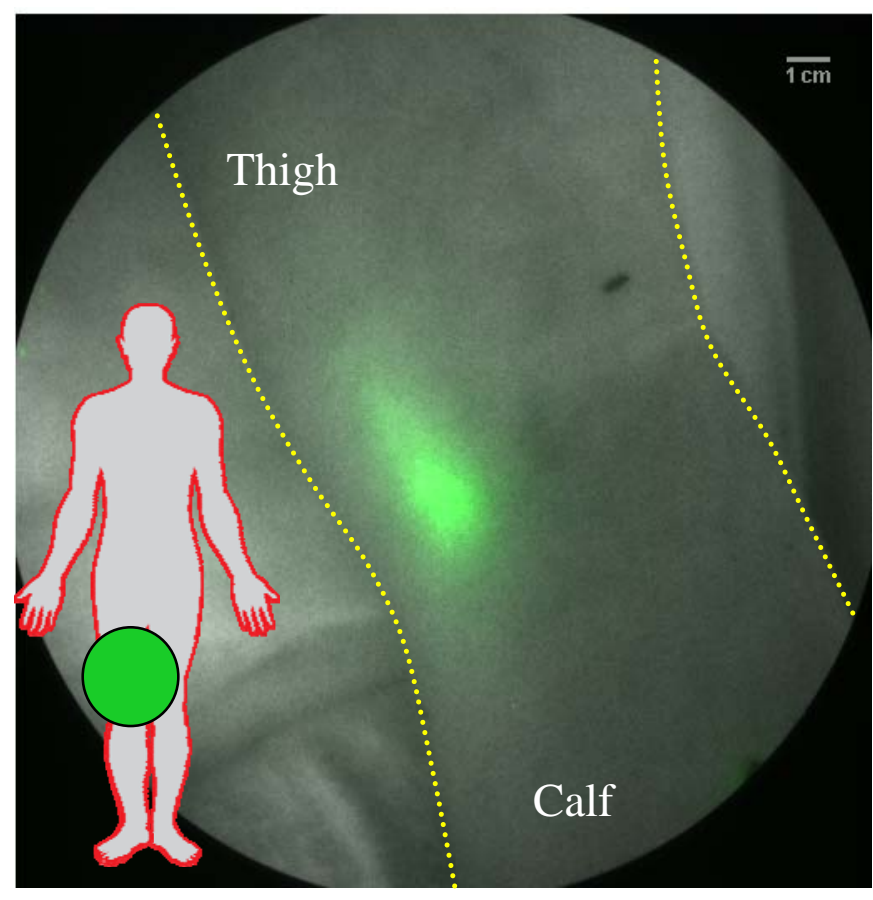

C

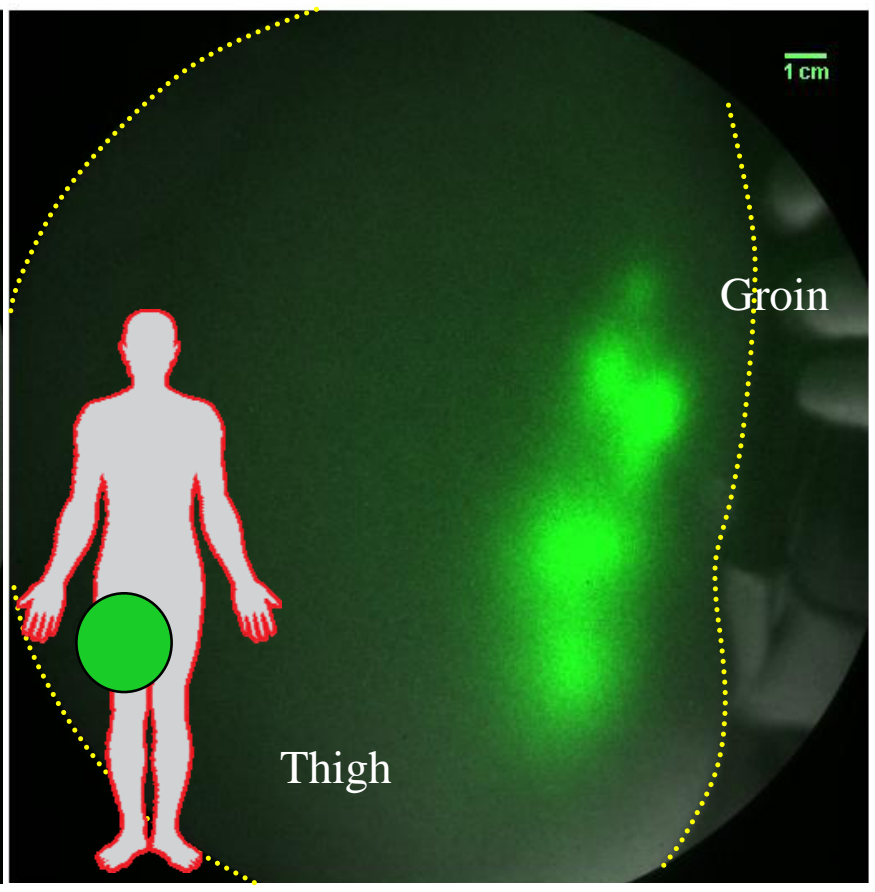

d

Fig. (3). Fluorescence images of nodal regions in normal subjects: (a) three median lymphatic bundles that pool the fluorescent dye into three lymph nodes in the axilla; (b) afferent and efferent lymphatic vessels feeding and draining the fluorescent cubital lymph node in the medial forearm and elbow; (c) the popliteal lymph node in the back of the right knee (d) fluorescent signals demarking up to six superficial inguinal lymph nodes. Reproduced from Sevick-Muraca [75] with permission.

fluorescence angiography to visualize arteriovenous malformations during surgical repair [59]. In plastic surgery, ICG fluorescence has been used to monitor blood flow in skin transplants [60-62].

\subsection{Oncology Imaging}

In another application of intraoperative imaging, Ishizawa and colleagues [63] injected $0.5 \mathrm{mg} / \mathrm{kg}$ ICG 


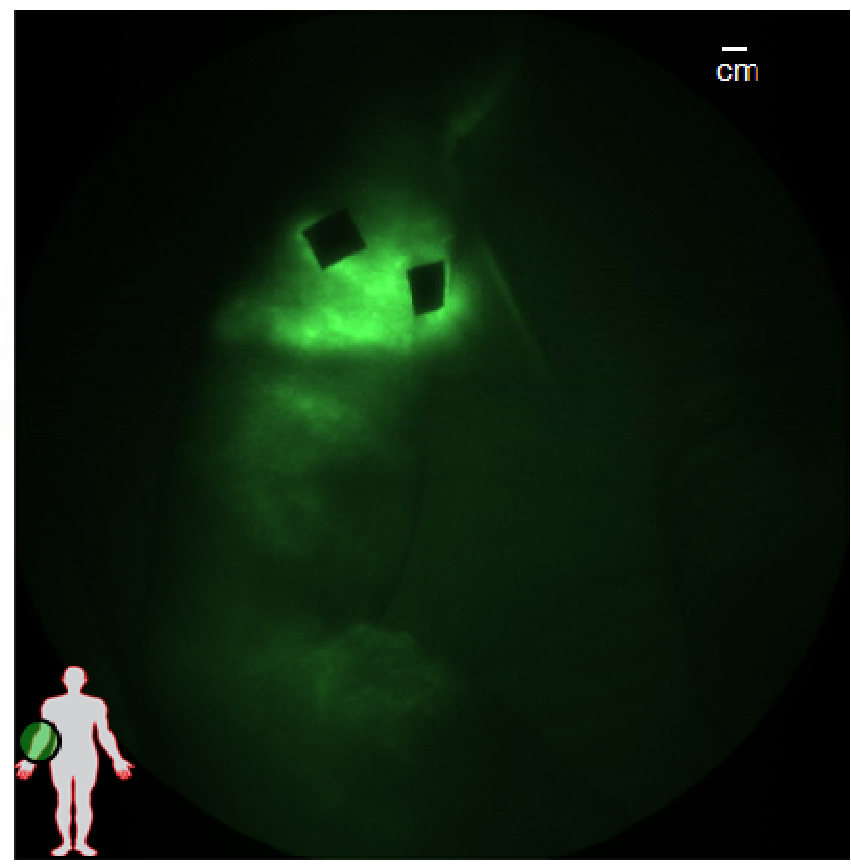

(a)

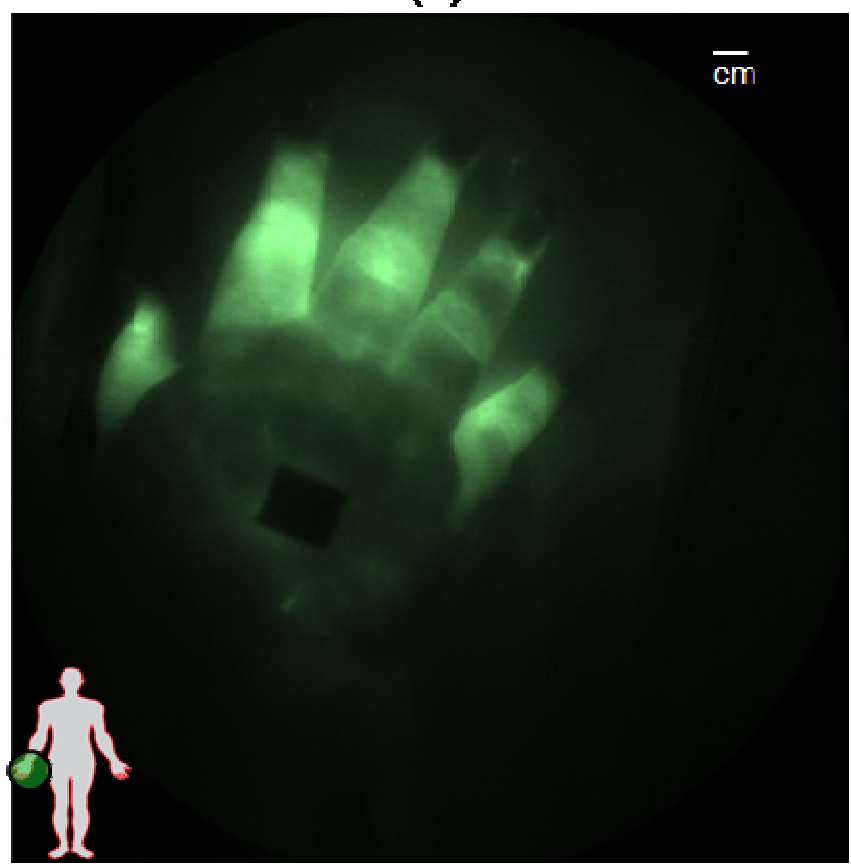

(c)

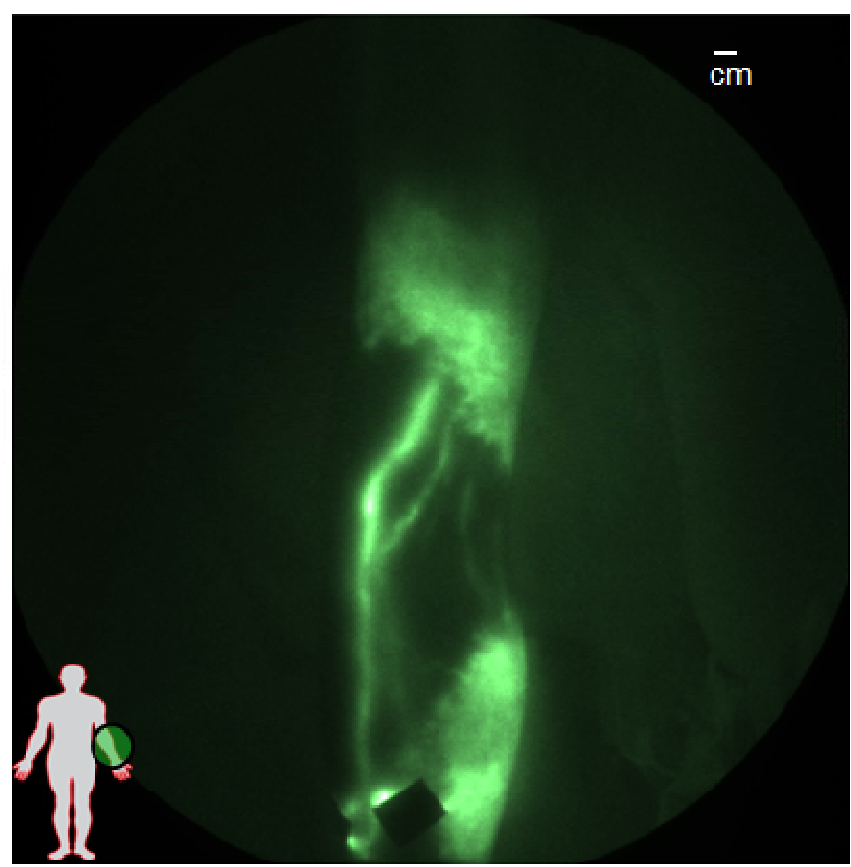

(b)

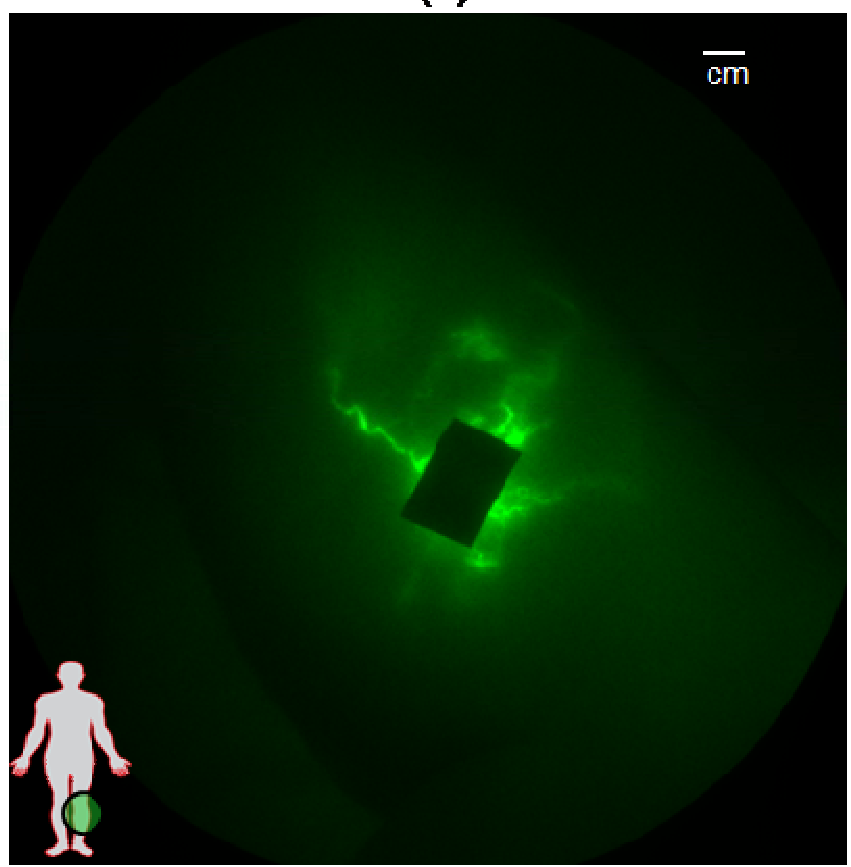

(d)

Fig. (4). Images of diseased lymphatics in lymphedema subjects: (a) diffused dye patterns in symptomatic arm, (b) hyperplastic growth in symptomatic arm, (c) retrograde flow in symptomatic hand, and (d) tortuous vessels in symptomatic leg. Black areas are covered injection sites. Reproduced from Rasmussen et al. [47].

intravenously prior to surgery as part of liver function testing, and $1-14$ days later intraoperatively imaged the surface of the liver to show both hepatocellular carcinoma and colon cancer metastases in situ. Imaging of specimens confirmed non-specific ICG fluorescence associated with disease, further suggesting that future image-guided resection with molecularly targeting conjugates labeled with a NIR fluorophore could improve surgery. In a similar manner, ICG was used to identify mammary carcinomas in breast cancer patients by the delayed clearance due to angiogenesis in the area of the tumors [64]. While fluorescence measurements were not collected, in the context of NIR fluorescence imaging devices, the study nonetheless demonstrates an opportunity to detect cancer on the basis of wash-out of ICG. 
Table 3. Listing of Adverse Events Associated with ICG (All Intravenous Administrations)

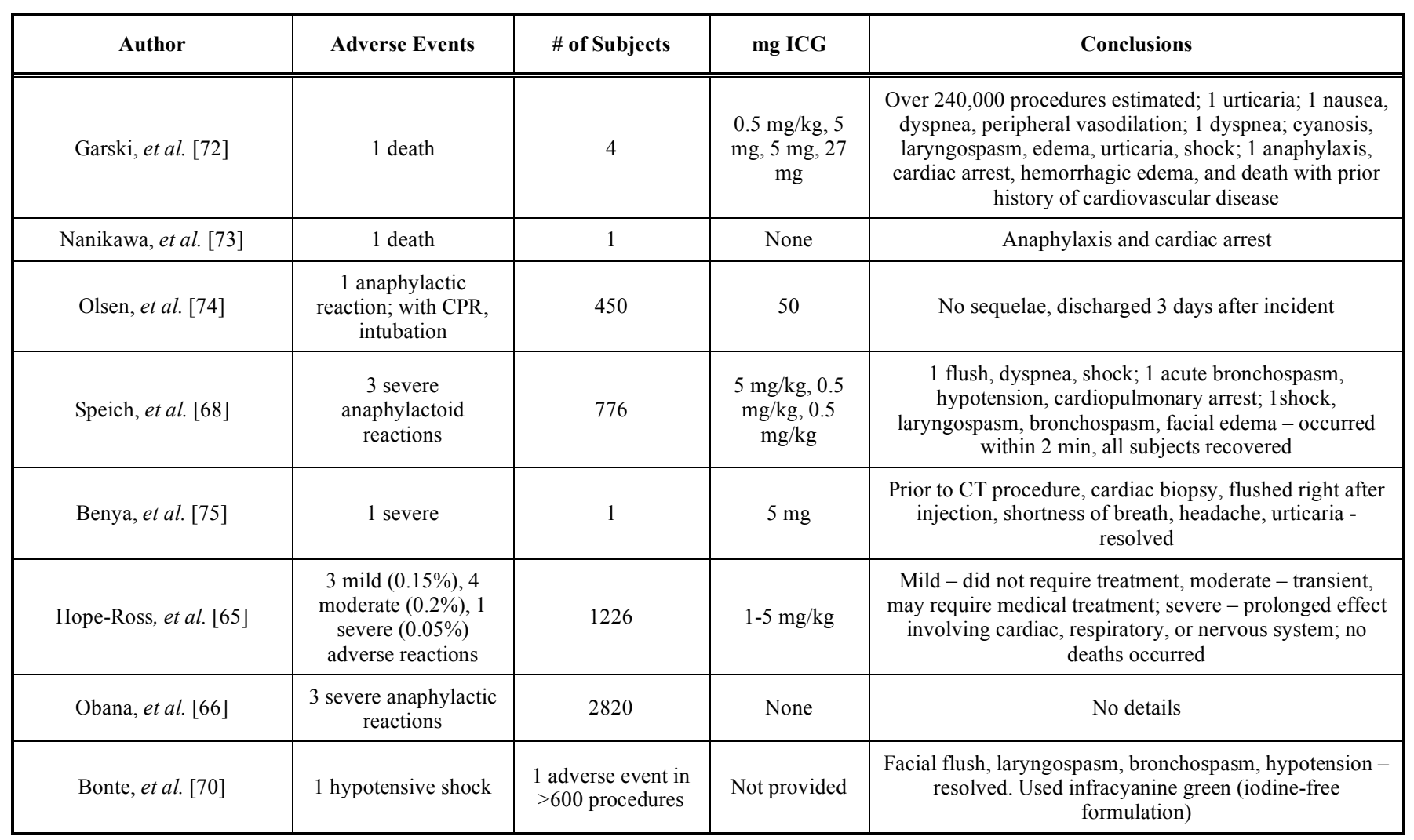

\subsection{Adverse Events Associated with ICG}

By far, the major use of ICG has been with intravenous administration, and usage by this route of administration has been approved for study of hepatic clearance, cardiac function, and retinal angiography. A sampling of published literature reports of adverse events associated with ICG administration is presented in Table 3. Published literature describes more than 6,200 uses of ICG by intravenous administration, with doses ranging from $1.5-50 \mathrm{mg}$. The recommended maximal dose in adults is $2 \mathrm{mg} / \mathrm{kg}$, and typically, no more than $25 \mathrm{mg}$ is administered for organ function tests. The incidence of mild adverse reactions was $0.05 \%$, and $0.05 \%$ for severe adverse reactions, with no deaths after 1923 procedures [65]. In a study of 2820 patients who underwent ICG angiography, the incidence rate of adverse events was $0.07 \%$ [66]. In comparison, the incidence rate reported for isosulfan blue dye in SLN identification was $1.1 \%$ [67]. No deaths occurred using ICG in 639 SLN biopsies, but hospitalization was prolonged in the subjects with anaphylaxis. In some cases, adverse events were associated with other co-morbidities, including preexisting drug allergy, severe asthma, and shellfish allergy [65]. Speich and coworkers [68] proposed that anaphylactoid reactions to ICG are pseudo-allergenic, as they do not involve IgE. Michie's studies [69] indicate that adverse reactions to ICG were due to non-immunologic histamine release, and that iodine or shellfish allergies were not predisposing factors in developing anaphylaxis. Infracyanine Green is an iodine-free preparation of ICG, and an anaphyactoid reaction to infracyanine green [70] would support the lack of iodine allergy as a cause of anaphylactic reactions to ICG that presumably occurred from residual iodide (approximately 5\%). Bonte [70] also supports a nonimmunogenic release of histamine as the cause of mild to moderate adverse reactions after exposure to ICG. These adverse reactions all occurred following IV administration of ICG doses higher than those used for intradermal or subcutaneous administration.

\section{OPPORTUNITIES AND LIMITATIONS FOR NIR IMAGING WITH ICG}

Clearly, there are significant opportunities for NIR fluorescence clinical imaging that are enhanced by (i) the small volumes and amounts of contrast agent compared to MR- and CT-based angiography procedures and (ii) the potentially high sensitivity of new molecular imaging techniques that may be used both non-invasively as well as intraoperatively. Even though ICG is a dim fluorophore in comparison to new dyes not yet tested in humans [26], clinical utility has been demonstrated using six NIR fluorescence imaging devices tested in human investigational studies. Indeed, at this early stage in its development, NIR fluorescence imaging has already provided new insights into the structure and function of the lymphatic circulatory system that have never been visualized before.

The advantage of NIR fluorescence imaging may well lie in its high photon count rate. As deeper tissue penetration reduces the photon count rate through tissue attenuation, the ability to reduce the noise floor through proper filtering and increase of camera integration times should overcome depth issues. Currently, depth of penetration for NIR fluorescence is estimated to be between 2 and $4 \mathrm{~cm}$ and could be improved if the noise floor of devices could be lowered. Using dual-labeled nuclear and NIR fluorescence imaging 
agents along with PET and NIR tomography [41], we are currently determining the depth to which NIR fluorophores can be assessed in phantom, animal, and ultimately in human studies.

Unfortunately, there have been no attempts or methods developed to standardize performance metrics of NIR fluorescence imaging devices, which unlike ultrasound, MR, $\mathrm{CT}$, and nuclear imaging techniques, are inherently dependent upon the spectral properties of the contrast agent employed. Indeed, Tables 1 and $\mathbf{2}$ show that each of the six devices thus far utilized in human studies have different excitation, filtering, and, most importantly, sensitivities for imaging ICG fluorescence. A consensus document for evaluating pertinent device performance metrics, such as camera integration times, working distance, field of view, and excitation light leakage, as described above Table 1, needs to be developed by the community to enable routine use of ICG and adoption of other NIR fluorophores. Such a consensus document would provide a reportable measure of effectiveness and sensitivity for each device and could accelerate the translation of clinical NIR fluorescence imaging and tomography.

\section{ABBREVIATIONS}

ALND $=$ Axillary lymph node dissection
$\mathrm{CCD}=$ Charge coupled device
$\mathrm{FDA}=$ Food and Drug Administration
FPDM $=$ Frequency Domain Photon Migration
$\mathrm{ICG}=$ Indocyanine Green
$\mathrm{ICH}=$ International Conference on Harmonization
$\mathrm{LN}=$ Lymph node
$\mathrm{NIR}=$ Near-infrared
SLN $=$ Sentinel lymph node
ACKNOWLEDGEMENTS

This work was supported in parts by the National Institutes of Health (R01 HL092923, R01 CA128919, U54 CA136404, and the Longaberger Foundation through the American Cancer Society (RSG 06-213-01-LR). The authors acknowledge the assistance of Ms. Jessica Nollkamper in the preparation of this manuscript.

\section{SUPPLEMENTARY MATERIAL}

Online supplemental video \#1: Lymphatic vessels propelling lymph in the right medial arm as shown by NIR fluorescence imaging and as described in Fig. (2) and text.

Online supplemental video \#2: Lymphatic vessel propelling lymph to the left axilla as shown by NIR fluorescence imaging and as described in Fig. (2) and text. The subject underwent left ALND 30 years prior to imaging and exhibits no symptoms of lymphedema.

Online supplemental video \#3: Lymphatic vessels propelling lymph to right medial arm as shown by NIR fluorescence imaging and as described in Fig. (2) and text.

\section{REFERENCES}

[1] Alitalo K, Tammela T, Petrova TV. Lymphangiogenesis in development and human disease. Nature 2005; 438(7070): 946-53.

[2] Rockson SG. Lymphedema. Am J Med 2001 Mar; 110(4): 288-95.

[3] Armer JM. The problem of post-breast cancer lymphedema: impact and measurement issues. Cancer Invest 2005; 23(1): 76-83.

[4] Ridner SH. Pretreatment lymphedema education and identified educational resources in breast cancer patients. Patient Educ Couns 2006; 61(1): 72-9.

[5] Mansel RE, Fallowfield L, Kissin M, et al. Randomized multicenter trial of sentinel node biopsy versus standard axillary treatment in operable breast cancer: the ALMANAC Trial. J Natl Cancer Inst 2006; 98(9): 599-609.

[6] de Vries M, Vonkeman WG, van Ginkel RJ, et al. Morbidity after inguinal sentinel lymph node biopsy and completion lymph node dissection in patients with cutaneous melanoma. Eur J Surg Oncol 2006; 32(7): 785-9.

[7] Finegold DN, Schacht V, Kimak MA, et al. HGF and MET mutations in primary and secondary lymphedema. Lymphat Res Biol 2008; 6(2): 65-8

[8] Stewart FW, Treves N. Lymphangiosarcoma in postmastectomy lymphedema; a report of six cases in elephantiasis chirurgica. Cancer 1948; 1(1): 64-81.

[9] Harvey NL, Srinivasan RS, Dillard ME, et al. Lymphatic vascular defects promoted by Prox 1 haploinsufficiency cause adult-onset obesity. Nat Genet 2005; 37(10): 1072-81.

[10] Qu P, Ji RC, Shimoda H, et al. Study on pancreatic lymphatics in nonobese diabetic mouse with prevention of insulitis and diabetes by adjuvant immunotherapy. Anat Rec A Discov Mol Cell Evol Biol 2004; 281(2): 1326-36.

[11] Ebina M. Remodeling of airway walls in fatal asthmatics decreases lymphatic distribution; beyond thickening of airway smooth muscle layers. Allergol Int 2008; 57(2): 165-74.

[12] Sleeman JP, Thiele W. Tumor metastasis and the lymphatic vasculature. Int J Cancer 2009; 125(12): 2747-56.

[13] Sharma R, Wendt JA, Rasmussen JC, et al. New horizons for imaging lymphatic function. Ann N Y Acad Sci 2008; 1131: 13-36. Szuba A, Shin WS, Strauss HW, et al. The third circulation: radionuclide lymphoscintigraphy in the evaluation of lymphedema. J Nucl Med 2003; 44(1): 43-57.

[15] Adams KE, Ke S, Kwon S, et al. Comparison of visible and nearinfrared wavelength-excitable fluorescent dyes for molecular imaging of cancer. J Biomed Opt 2007; 12(2): 024017.

[16] Sevick-Muraca EM, Rasmussen JC. Molecular imaging with optics: primer and case for near-infrared fluorescence techniques in personalized medicine. J Biomed Opt 2008; 13(4): 041303.

[17] Hwang K, Houston JP, Rasmussen JC, Ke S, Li C, Sevick-Muraca EM. Enhanced fluorescence optical imaging with improved excitation light rejection. Mol Imaging 2005; 4(3): 194-204.

[18] Houston JP, Thompson AB, Gurfinkel M, et al. Sensitivity and depth penetration of continuous wave versus frequency-domain photon migration near-infrared fluorescence contrast-enhanced imaging. Photochem Photobiol 2003; 77(4): 420-30.

[19] Murawa D, Hirche C, Dresel S, et al. Sentinel lymph node biopsy in breast cancer guided by indocyanine green fluorescence. $\mathrm{Br} \mathrm{J}$ Surg 2009; 96(11): 1289-94.

[20] Reynolds JS, Troy TL, Mayer RH, et al. Imaging of spontaneous canine mammary tumors using fluorescent contrast agents. Photochem Photobiol 1999; 70(1): 87-94.

[21] Gurfinkel M, Thompson AB, Ralston W, et al. Pharmacokinetics of ICG and HPPH-car for the detection of normal and tumor tissue using fluorescence, near-infrared reflectance imaging: a case study. Photochem Photobiol 2000; 72(1): 94-102.

[22] Sevick-Muraca EM, Sharma R, Rasmussen JC, et al. Imaging of lymph flow in breast cancer patients after microdose administration of a near-infrared fluorophore: feasibility study. Radiology 2008 ; 246(3): 734-41.

[23] Troyan SL, Kianzad V, Gibbs-Strauss SL, et al. The FLARE intraoperative near-infrared fluorescence imaging system: a first-inhuman clinical trial in breast cancer sentinel lymph node mapping. Ann Surg Oncol 2009 ; 16(10): 2943-52. 
[24] Reuthebuch O, Haussler A, Genoni M, et al. Novadaq SPY: intraoperative quality assessment in off-pump coronary artery bypass grafting. Chest 2004; 125(2): 418-24.

[25] Handa T, Katare RG, Sasaguri S, et al. Preliminary experience for the evaluation of the intraoperative graft patency with real color charge-coupled device camera system: an advanced device for simultaneous capturing of color and near-infrared images during coronary artery bypass graft. Interact Cardiovasc Thorac Surg 2009; 9(2): 150-4.

[26] Marshall MV, Draney D, Sevick-Muraca EM, et al. Single dose intravenous toxicity study of IRDye $800 \mathrm{CW}$ in Sprague-Dawley rats. Mol Imaging Biol 2010; in press.

[27] Barthelmes L, Goyal A, Newcombe RG, et al. Adverse reactions to patent blue V dye - The NEW START and ALMANAC experience. Eur J Surg Oncol 2009 Nov 23.

[28] Ikeda T, Jinno H, Fujii H, et al. Recent development of sentinel lymph node biopsy for breast cancer in Japan. Asian J Surg 2004; 27(4): 275-8.

[29] Motomura K, Inaji H, Komoike Y, et al. Sentinel node biopsy guided by indocyanine green dye in breast cancer patients. Jpn J Clin Oncol 1999; 29(12): 604-7.

[30] Ichikura T, Chochi K, Sugasawa H, et al. Individualized surgery for early gastric cancer guided by sentinel node biopsy. Surgery 2006 ; 139(4): 501-7.

[31] Yaguchi Y, Ichikura $\mathrm{T}$, Ono $\mathrm{S}$, et al. How should tracers be injected to detect for sentinel nodes in gastric cancer--submucosally from inside or subserosally from outside of the stomach? J Exp Clin Cancer Res 2008; 27: 79.

[32] Park DJ, Lee HJ, Lee HS, et al. Sentinel node biopsy for cT1 and cT2a gastric cancer. Eur J Surg Oncol 2006; 32(1): 48-54.

[33] Fujiwara M, Mizukami T, Suzuki A, et al. Sentinel lymph node detection in skin cancer patients using real-time fluorescence navigation with indocyanine green: preliminary experience. J Plast Reconstr Aesthet Surg 2009; 62(10): e373-8.

[34] Tagaya N, Yamazaki R, Nakagawa A, et al. Intraoperative identification of sentinel lymph nodes by near-infrared fluorescence imaging in patients with breast cancer. Am J Surg 2008; 195(6): 850-3.

[35] Miyashiro I, Miyoshi N, Hiratsuka M, et al. Detection of sentinel node in gastric cancer surgery by indocyanine green fluorescence imaging: comparison with infrared imaging. Ann Surg Oncol 2008; 15(6): 1640-3.

[36] Kitai T, Inomoto T, Miwa M, et al. Fluorescence navigation with indocyanine green for detecting sentinel lymph nodes in breast cancer. Breast Cancer 2005; 12(3): 211-5.

[37] Tsujino Y, Mizumoto K, Matsuzaka Y, et al. Fluorescence navigation with indocyanine green for detecting sentinel nodes in extramammary Paget's disease and squamous cell carcinoma. J Dermatol 2009; 36(2): 90-4.

[38] Tanaka R, Nakashima K, Fujimoto W. Sentinel lymph node detection in skin cancer using fluorescence navigation with indocyanine green. J Dermatol 2009; 36(8): 468-70.

[39] Ogasawara Y, Ikeda H, Takahashi M, et al. Evaluation of breast lymphatic pathways with indocyanine green fluorescence imaging in patients with breast cancer. World J Surg 2008; 32(9): 1924-9.

[40] Noura S, Ohue M, Seki Y, et al. Feasibility of a lateral region sentinel node biopsy of lower rectal cancer guided by indocyanine green using a near-infrared camera system. Ann Surg Oncol 2009 Sep 23.

[41] Hawrysz DJ, Sevick-Muraca EM. Developments toward diagnostic breast cancer imaging using near-infrared optical measurements and fluorescent contrast agents. Neoplasia 2000; 2(5): 388-417.

[42] Guidance for industry, investigators, and reviewers exploratory IND studies. In: U.S. Department of Health and Human Services CfDEaR, Rockville MD, Ed. USA: U.S. Department of Health and Human Services; 2006.

[43] Unno N, Inuzuka K, Suzuki M, et al. Preliminary experience with a novel fluorescence lymphography using indocyanine green in patients with secondary lymphedema. J Vasc Surg 2007; 45(5): $1016-21$.

[44] Unno N, Nishiyama M, Suzuki M, et al. Quantitative lymph imaging for assessment of lymph function using indocyanine green fluorescence lymphography. Eur J Vasc Endovasc Surg 2008; 36(2): 230-6.

[45] Suzuki M, Unno N, Yamamoto N, et al. Impaired lymphatic function recovered after great saphenous vein stripping in patients with varicose vein: venodynamic and lymphodynamic results. J Vasc Surg 2009; 50(5): 1085-91.

[46] Sharma R, Wang W, Rasmussen JC, et al. Quantitative imaging of lymph function. Am J Physiol Heart Circ Physiol 2007; 292(6): H3109-18.

[47] Kwon S, Sevick-Muraca EM. Noninvasive quantitative imaging of lymph function in mice. Lymphat Res Biol 2007; 5(4): 219-31.

[48] Rasmussen JC, Tan IC, Marshall MV, et al. Lymphatic imaging in humans with near-infrared fluorescence. Curr Opin Biotechnol 2009; 20(1): 74-82.

[49] Rasmussen JC, Tan IC, Marshall MV, et al. Human lymphatic architecture and (dys)function imaged using near-infrared fluorescence: Part 1. 2010; submitted.

[50] Tan IC, Maus EA, Rasmussen JC, et al. NIR fluorescence imaging of improved lymphatic propulsion and transport following maunal lymph drainage: part 2. 2010; submitted.

[51] Kamiya K, Unno N, Konno H. Intraoperative indocyanine green fluorescence lymphography, a novel imaging technique to detect a chyle fistula after an esophagectomy: report of a case. Surg Today 2009; 39(5): 421-4.

[52] Ogata F, Narushima M, Mihara M, et al. Intraoperative lymphography using indocyanine green dye for near-infrared fluorescence labeling in lymphedema. Ann Plast Surg 2007; 59(2): 180-4.

[53] Kikuchi M, Hosokawa K. Near-infrared fluorescence venography: a navigation system for varicose surgery. Dermatol Surg 2009; 35(10): 1495-8.

[54] Balacumaraswami L, Abu-Omar Y, Anastasiadis K, et al. Does offpump total arterial grafting increase the incidence of intraoperative graft failure? J Thorac Cardiovasc Surg 2004; 128(2): 238-44.

[55] Balacumaraswami L, Abu-Omar Y, Choudhary B, et al. A comparison of transit-time flowmetry and intraoperative fluorescence imaging for assessing coronary artery bypass graft patency. J Thorac Cardiovasc Surg 2005; 130(2): 315-20.

[56] Rubens FD, Ruel M, Fremes SE. A new and simplified method for coronary and graft imaging during CABG. Heart Surg Forum 2002; 5(2): 141-4.

[57] Taggart DP, Choudhary B, Anastasiadis K, et al. Preliminary experience with a novel intraoperative fluorescence imaging technique to evaluate the patency of bypass grafts in total arterial revascularization. Ann Thorac Surg 2003; 75(3): 870-3.

[58] Sekijima M, Tojimbara T, Sato S, et al. An intraoperative fluorescent imaging system in organ transplantation. Transplant Proc 2004; 36(7): 2188-90.

[59] Killory BD, Nakaji P, Gonzales LF, et al. Prospective evaluation of surgical microscope-integrated intraoperative near-infrared indocyanine green angiography during cerebral arteriovenous malformation surgery. Neurosurgery 2009; 65(3): 456-62; discussion 62.

[60] Holm C, Mayr M, Hofter E, et al. Intraoperative evaluation of skinflap viability using laser-induced fluorescence of indocyanine green. Br J Plast Surg 2002; 55(8): 635-44.

[61] Holm C, Mayr M, Hofter E, et al. Perfusion zones of the DIEP flap revisited: a clinical study. Plast Reconstr Surg 2006; 117(1): 37-43.

[62] Holm C, Tegeler J, Mayr M, et al. Monitoring free flaps using laser-induced fluorescence of indocyanine green: a preliminary experience. Microsurgery 2002; 22(7): 278-87.

[63] Ishizawa T, Bandai Y, Kokudo N. Fluorescent cholangiography using indocyanine green for laparoscopic cholecystectomy: an initial experience. Arch Surg 2009; 144(4): 381-2.

[64] Alacam B, Yazici B, Intes X, et al. Pharmacokinetic-rate images of indocyanine green for breast tumors using near-infrared optical methods. Phys Med Biol 2008 21; 53(4): 837-59.

[65] Hope-Ross M, Yannuzzi LA, Gragoudas ES, Guyer DR, Slakter JS, Sorenson JA, et al. Adverse reactions due to indocyanine green. Ophthalmology 1994; 101(3): 529-33.

[66] Obana A, Miki T, Hayashi K, et al. Survey of complications of indocyanine green angiography in Japan. Am J Ophthalmol 1994 $15 ; 118(6): 749-53$.

[67] Albo D, Wayne JD, Hunt KK, et al. Anaphylactic reactions to isosulfan blue dye during sentinel lymph node biopsy for breast cancer. Am J Surg 200; 182(4): 393-8.

[68] Speich R, Saesseli B, Hoffmann U, et al. Anaphylactoid reactions after indocyanine-green administration. Ann Intern Med 1988 15; 109(4): 345-6. 
[69] Michie DD, Wombolt DG, Carretta RF, et al. Adverse reactions associated with the administration of a tricarbocyanine dye (Cardio-Green) to uremic patients. J Allergy Clin Immunol 1971; 48(4): 235-9.

[70] Bonte CA, Ceuppens J, Leys AM. Hypotensive shock as a complication of infracyanine green injection. Retina 1998; 18(5): 476-7.

[71] Tajima Y, Yamazaki K, Masuda Y, et al. Sentinel node mapping guided by indocyanine green fluorescence imaging in gastric cancer. Ann Surg 2009; 249(1): 58-62.
[72] Garski TR, Staller BJ, Hepner G, et al. Adverse reactions after administration of indocyanine green. JAMA 1978 18; 240(7): 635.

[73] Nanikawa R, Hayashi T, Hayashi K. A case of fatal shock induced by indocyanine green (ICG) test. Jap J Leg Medicine 1978; 32: 209-14.

[74] Olsen TW, Lim JI, Capone A, et al. Anaphylactic shock following indocyanine green angiography. Arch Ophthalmol 1996; 114(1): 97.

[75] Benya R, Quintana J, Brundage B. Adverse reactions to indocyanine green: a case report and a review of the literature. Cathet Cardiovasc Diagn 1989; 17(4): 231-3.

Received: December 7, 2009

Revised: December 23, 2009

Accepted: December 23, 2009

(C) Marshall et al.; Licensee Bentham Open.

This is an open access article licensed under the terms of the Creative Commons Attribution Non-Commercial License (http://creativecommons.org/licenses/by$\mathrm{nc} / 3.0 /$ ) which permits unrestricted, non-commercial use, distribution and reproduction in any medium, provided the work is properly cited. 